\title{
Validation of a smartphone-based Rinne test to detect an air-bone gap
}

\author{
Daniel Hibscher ${ }^{1} \cdot$ Yahav $_{\text {Oron }}{ }^{1} \cdot$ Ophir Handzel $^{1} \cdot$ Anton Warshavsky $^{1} \cdot$ Gilad Horowitz $^{1} \cdot$ Omer J. Ungar $^{1}$ (1)
}

Received: 3 November 2020 / Accepted: 5 January 2021 / Published online: 16 January 2021

(c) The Author(s), under exclusive licence to Springer-Verlag GmbH, DE part of Springer Nature 2021

\begin{abstract}
Objective To validate a smartphone-based Rinne test employing the vibration application of mobile telephones. Study design Prospective controlled clinical study.

Setting Tertiary referral medical center.

Methods Twenty consecutive patients hospitalized in the otolaryngology department of a tertiary medical center due to unilateral hearing loss (HL study group), and 30 consecutive inpatients on the same ward who had no otological history (controls) were enrolled. Each participant underwent the traditional $512 \mathrm{~Hz}$ tuning fork-based Rinne test, as well as a smartphone-based Rinne test by means of a single uncovered smartphone with a vibration application. The test results were compared to those of formal audiometry.

Results The overall agreement between the traditional Rinne test and the smartphone-based test was $98 \%$. The Sensitivity was $85 \%$ for both tests, specificity was $90 \%$ and $93 \%$ for smartphone and tuning fork tests, respectively. The smartphonebased Rinne test could correctly discriminate between patients with an air-bone gap $\geq 25 \mathrm{~dB}$ at $512 \mathrm{~Hz}$ from patients with a lower or no air-bone gap at $512 \mathrm{~Hz}$. The smartphone-based Rinne could not evaluate two patients with a moderately severe/ severe sensorineural hearing loss due to their inability to detect the vibrations.

Conclusion A smartphone-based Rinne test was validated for the detection of an air-bone gap $\geq 25 \mathrm{~dB}$ at $512 \mathrm{~Hz}$ in the clinical setting. The validity of patient-operated smartphone-based Rinne test awaits further study.

Level of evidence $2 \mathrm{~B}$.
\end{abstract}

Keywords Hearing loss $\cdot$ Sudden sensorineural hearing loss $\cdot$ Rinne test $\cdot$ Conductive hearing loss $\cdot$ Tuning fork

\section{Introduction}

The air conduction (AC) threshold is lower than the bone conduction (BC) threshold when the audiologic pathway is intact. The Rinne test is a bedside examination that compares the two thresholds, and it is used to detect a conductive hearing loss (CHL) [1]. It is traditionally performed by placing the vibrating tuning fork on the mastoid process until the subject cannot hear the sound due to vibration decay (BC threshold). The tuning fork is then held $3-4 \mathrm{~cm}$ adjacent to external auditory canal. If the subject hears the signal emitted from the vibrating fork it means the AC signal

Omer J. Ungar

ungaromer@gmail.com

1 Department of Otolaryngology Head, Neck and Maxillofacial Surgery, Tel Aviv Sourasky Medical Center, Affiliated to the Sackler School of Medicine, Tel Aviv University, 6 Weizmann Street, 6423906 Tel Aviv, Israel transmission is better than the $\mathrm{BC}$, and thus the interpretation is Positive Rinne with presumed CHL [2]. In the case of CHL with a greater degree of loss, $\mathrm{AC}$ will be worse than $\mathrm{BC}$, and the Rinne test is said to be negative $(\mathrm{BC}<\mathrm{AC})$. The degree of CHL needed to change the Rinne test result is frequency specific [3], and it is more successfully performed with a $512 \mathrm{~Hz}$ tuning fork [4-7].

The Rinne test is one of the ubiquitous clinical tests for differentiation of CHL in otolaryngologic practice. While it can easily be carried out by general practitioners when a CHL is suspected [8], tuning forks are usually not available in their clinics.

The utility of telemedicine had been especially relevant in remote areas, but the COVID-19 pandemic has made it highly popular in urban areas as well. The universal use of smartphones made several validated applications in the field of otolaryngology available to clinicians and patients [9]. For example, the vibrating application of smartphones was validated for use as a $512 \mathrm{~Hz}$ tuning fork for the Weber test 
[10]. The aim of the current study is to similarly compare the traditional $512 \mathrm{~Hz}$ tuning fork-based Rinne test and formal audiometry, to a smartphone-based Rinne test.

\section{Materials and methods}

\section{Study population}

This prospective controlled study was approved by the research ethics committee of a tertiary referral medical center (0580-12-TLV). Included were adult patients who were hospitalized in the Department of Otolaryngology, Head and Neck and Maxillofacial Surgery. The study group was composed of consecutive patients who were hospitalized due to otologic conditions resulting in a CHL or a sensorineural hearing loss (SNHL) and who underwent a formal audiogram on the same day of study entry. The control group was composed of patients hospitalized in the same ward for any other reason with no suspicion for an otologic condition according to medical history and physical examination (Fig. 1).

\section{Materials}

The traditional tuning fork-based Rinne test was performed with a single $512 \mathrm{~Hz}$ tuning fork (AESCULAP OF003N CE) (Fig. 2). The smartphone-based Rinne test was performed with a single uncovered Samsung Galaxy J5 (2016; model SM-J510F) smartphone. The vibrating application was 'Vibrator' (Ape Studios), which is available without cost via Google Play Store.

The fundamental frequency (F0) and harmonics of the tuning fork and smartphone were measured using Praat software (version 6.0.46), which is a free computerized software package for the scientific analysis of speech in phonetics. The F0 of our tuning fork was measured as being in the range of $512 \mathrm{~Hz}$. The sound was not a pure tone but rather composed of closely related frequencies, probably due to mild corrosion. The smartphone's single vibration period was measured as being $0.0066761 \mathrm{~s}$, resulting in a basic frequency of $150.2 \mathrm{~Hz}$. F2 and F3 were enhanced at $300.4 \mathrm{~Hz}$ and $450.6 \mathrm{~Hz}$, respectively (Fig. 3).

\section{Methods}

After taking a medical history, each participant underwent a physical examination by a single otolaryngologist who administered both the traditional $512 \mathrm{~Hz}$ tuning fork-based Rinne test and the smartphone-based Rinne test. The tests were performed on the affected ear of the study group and on a randomly chosen ear of the control group. The traditional Rinne test was performed by striking and placing the tuning fork on the mastoid process. When the patient indicated that he/she no longer heard the tone, the tuning fork was repositioned perpendicularly and adjacent to the external auditory meatus [11]. The smartphone-based Rinne test was performed by adhering the bottom end of the smartphone to the mastoid process, followed by repositioning of the bottom end next to the external auditory meatus (Fig. 4).

Demographics, otologic pathology, and Rinne tests results, and formal audiograms of all the study participants were compared, and past medical and surgical histories were recorded as well. Clinical decision making was unaffected by any of the findings of the Rinne tests performed for this study.
Fig. 1 Flowchart of the cohort, sheowing inclusion and exclusion criteria

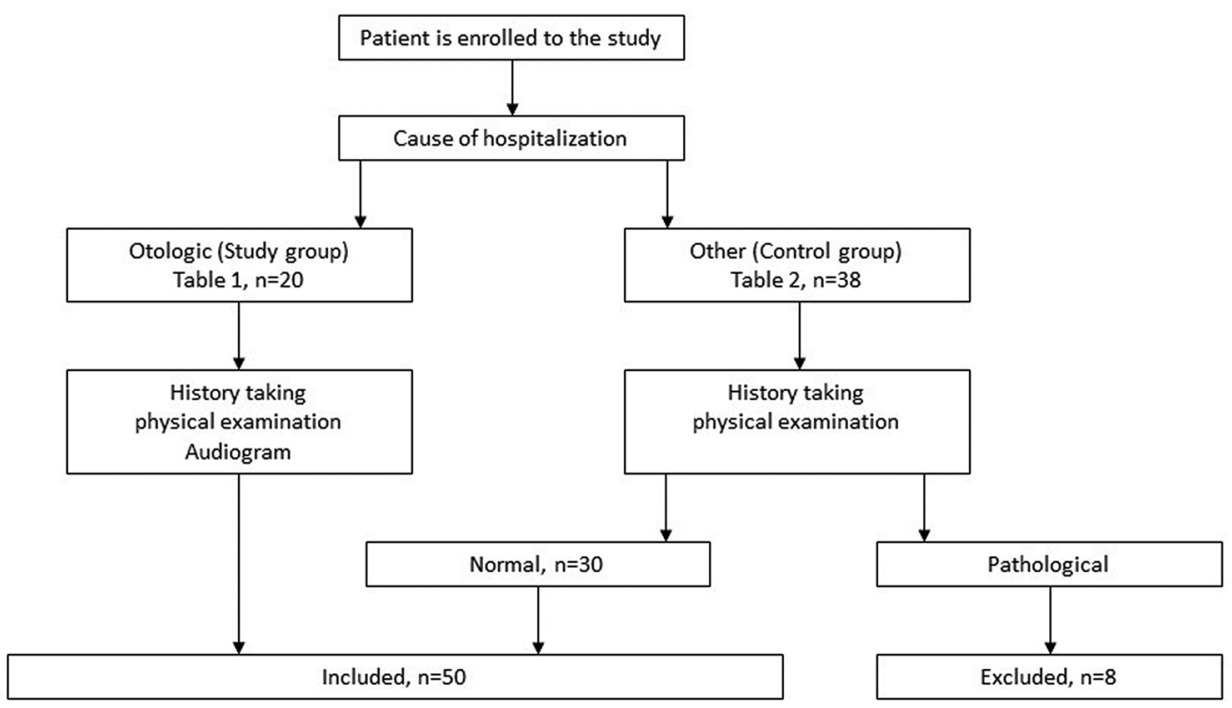


Fig. 2 The tuning forks used in the study

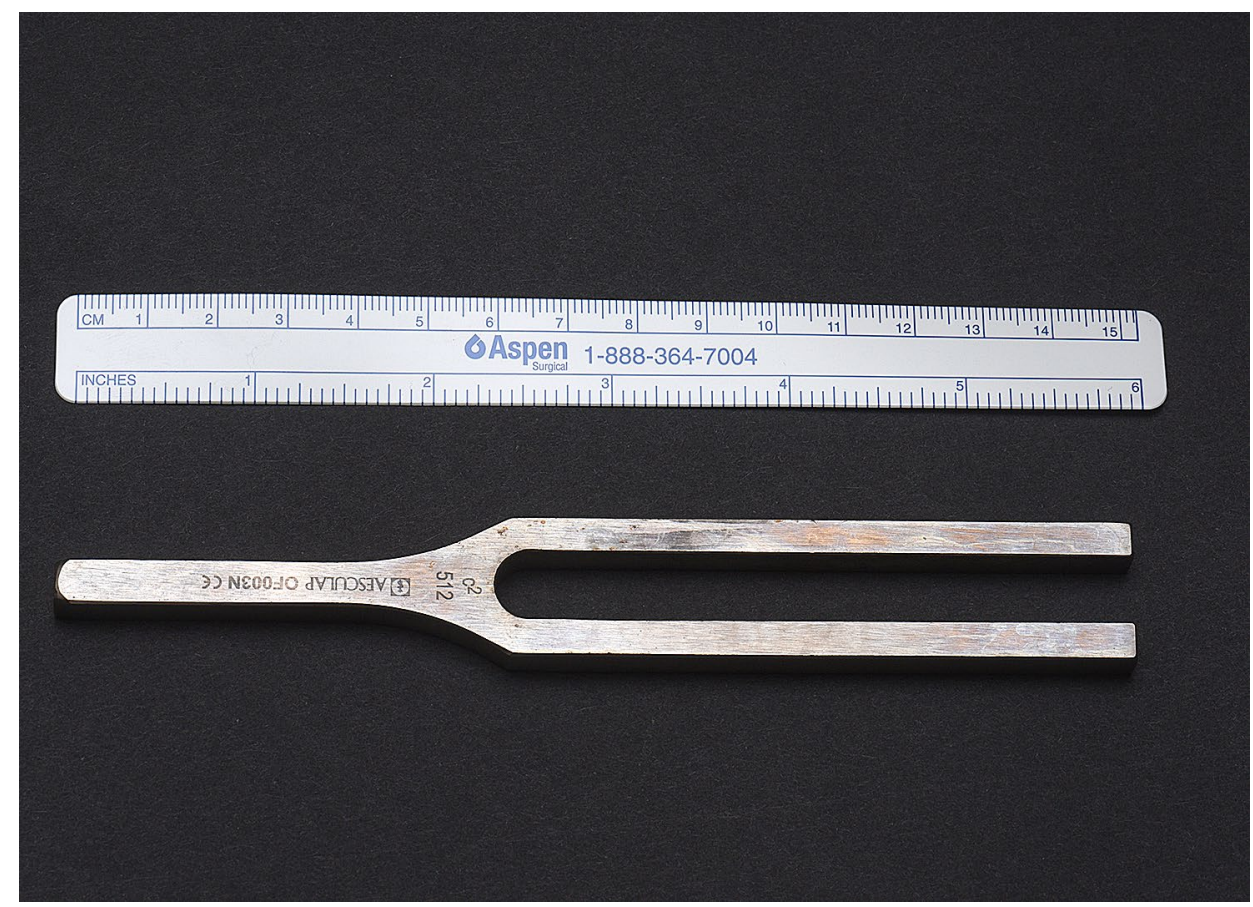

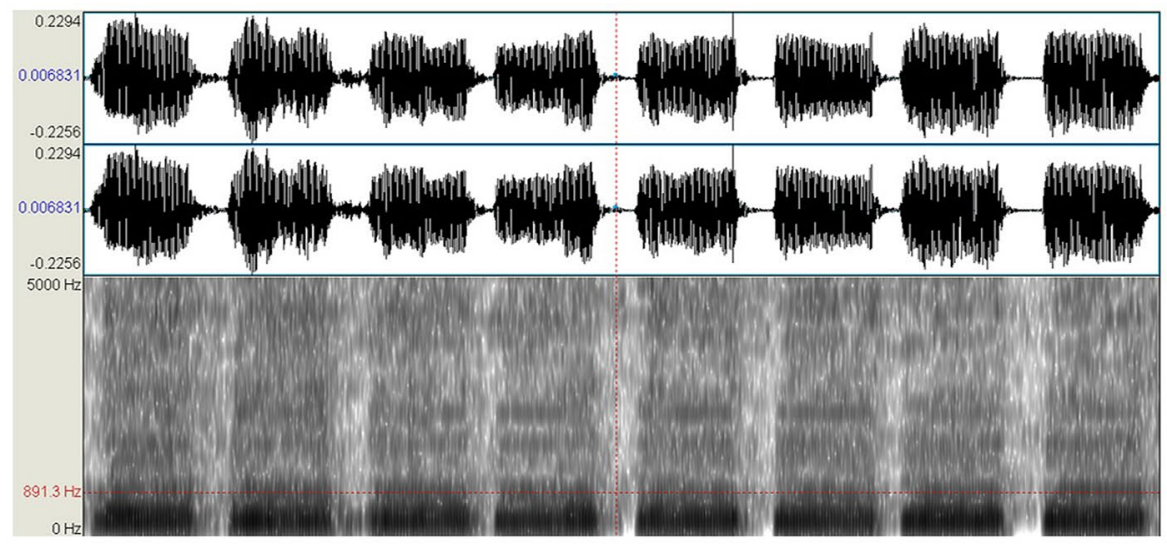

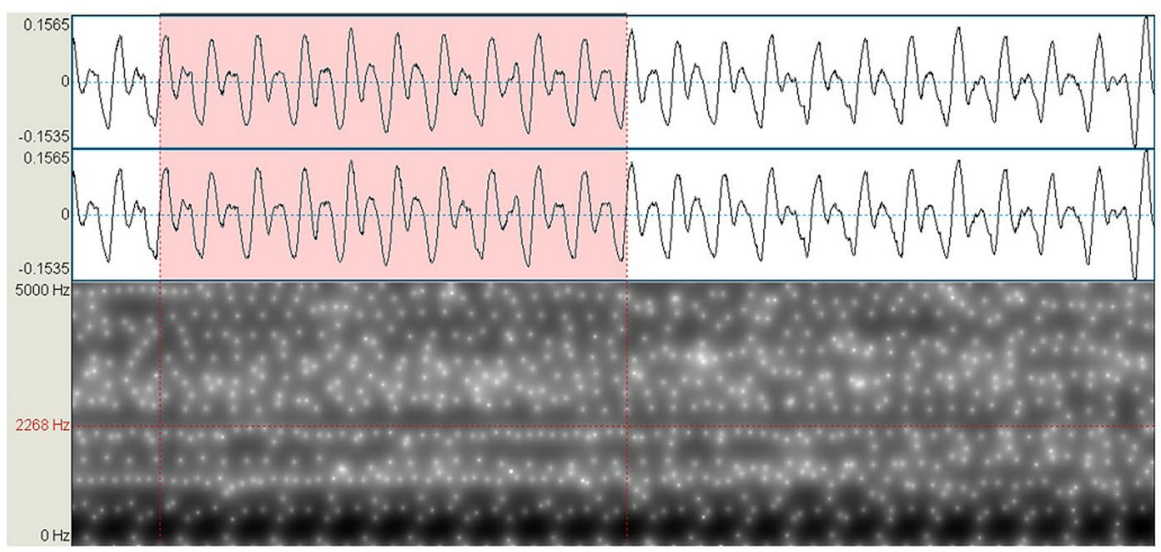

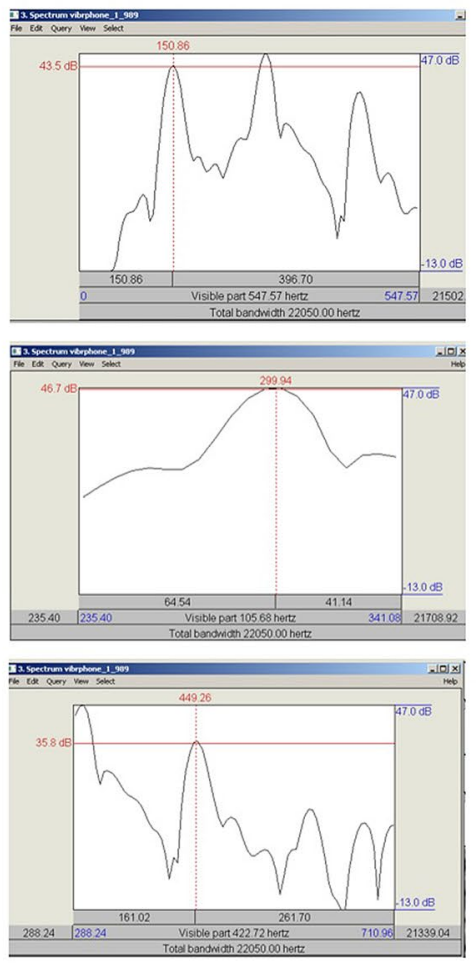

Fig. 3 The measured basic frequency of the vibrating smartphone, using Praat software (version 6.0.46) 
Fig. 4 The smartphone-based Rinne test performance

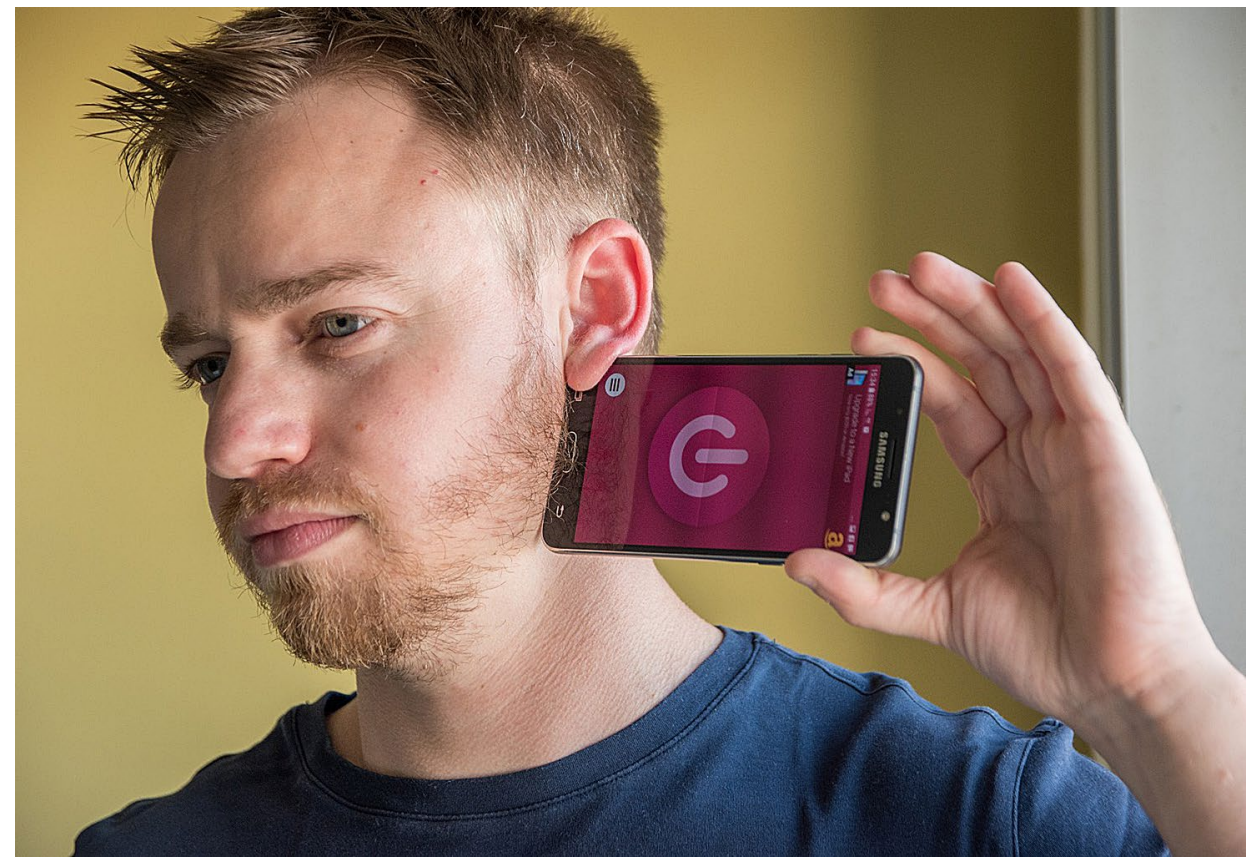

\section{Results}

Fifty patients met the inclusion criteria and participated in this study. The study group consisted of 20 patients (average age 37 years, range 19-55 years, 13 males). The underlying pathology for the CHLs (15patients) included serous otitis media (five patients), followed by cholesteatoma, otosclerosis, and tympanic membrane perforation (three patients each), and osteoma that occluded the external auditory canal (one patient). The cause of SNHL (five patients) was idiopathic sudden hearing loss (three patients), progressive HL due to vestibular schwannoma (one patient), and cisplatin-associated ototoxicity (one patient). The right and left ears were affected in a ratio of 8:12 (Table 1). The control group consisted of 30 patients (average age 41 years, range 18-69 years, 17 males) (Table 2). There were no significant differences in sex or age distributions between the groups $(P=0.80)$.

The smartphone-based Rinne test was in agreement with the traditional Rinne test in 49 (98\%) cases. The only mismatch was a 69-year-old patient in the control group who was admitted for total thyroidectomy due to benign pathology. The result of his traditional Rinne test with a $512 \mathrm{~Hz}$ tuning fork was positive, but he did not detect the vibration emitted by the smartphone when it was applied on the mastoid process or near the external auditory canal opening.

Fifteen study group patients had a CHL with an air-bone gap (ABG) at $512 \mathrm{~Hz}$ that was confirmed by formal audiometry. The ABG was $\geq 25 \mathrm{~dB}$ with a normal to slight sensorineural component at $512 \mathrm{~Hz}$ for 12 patients, and both the traditional and smartphone-based
Rinne tests were negative for all of them. In the remaining three CHL patients, the $512 \mathrm{~Hz}$ ABG was $\leq 20 \mathrm{~dB}$, with a normal hearing threshold for $512 \mathrm{~Hz}$, which resulted in positive traditional and positive smartphone-based Rinne test results. The five patients in the study group with SNHLs had an ABG no greater than $10 \mathrm{~dB}$ at $512 \mathrm{~Hz}$, and presented with mild, moderately severe, and severe HLs (two, two, and one patient, respectively). The two patients with the mild HLs had positive Rinne tests with both methods. The other three patients (two with a moderately severe SNHL and one with a severe SNHL) failed to detect both the tuning fork and the smartphone stimuli. All of the Rinne tests results and the related ABGs are listed in Table 1. Eight patients of the study group underwent medical interventions (e.g., Tympanostomy with ventilation tube insertion, stapes surgery, Myringoplasty) that resulted in reduced ABGs. Those patients underwent additional (post-treatment) Rinne tests by means of both methods, and the post-treatment Rinne tests were now positive in all of them. The post-treatment ABG of one patient failed to close (cholesteatoma resection without hearing rehabilitation, resulting in the maximal $\mathrm{ABG}$ ). That patient retained his negative traditional and smartphone-based Rinne test results.

No audiogram had been performed to exclude ABGs in the control group, but medical history and physical examination did not raise any suspicion of a HL. The traditional and smartphone-based Rinne tests were positive in 27 patients. Three patients (all over 60 years of age) failed to detect the vibration emitted by the smartphone, and two of them failed to detect the traditional $512 \mathrm{~Hz}$ tuning fork vibration 


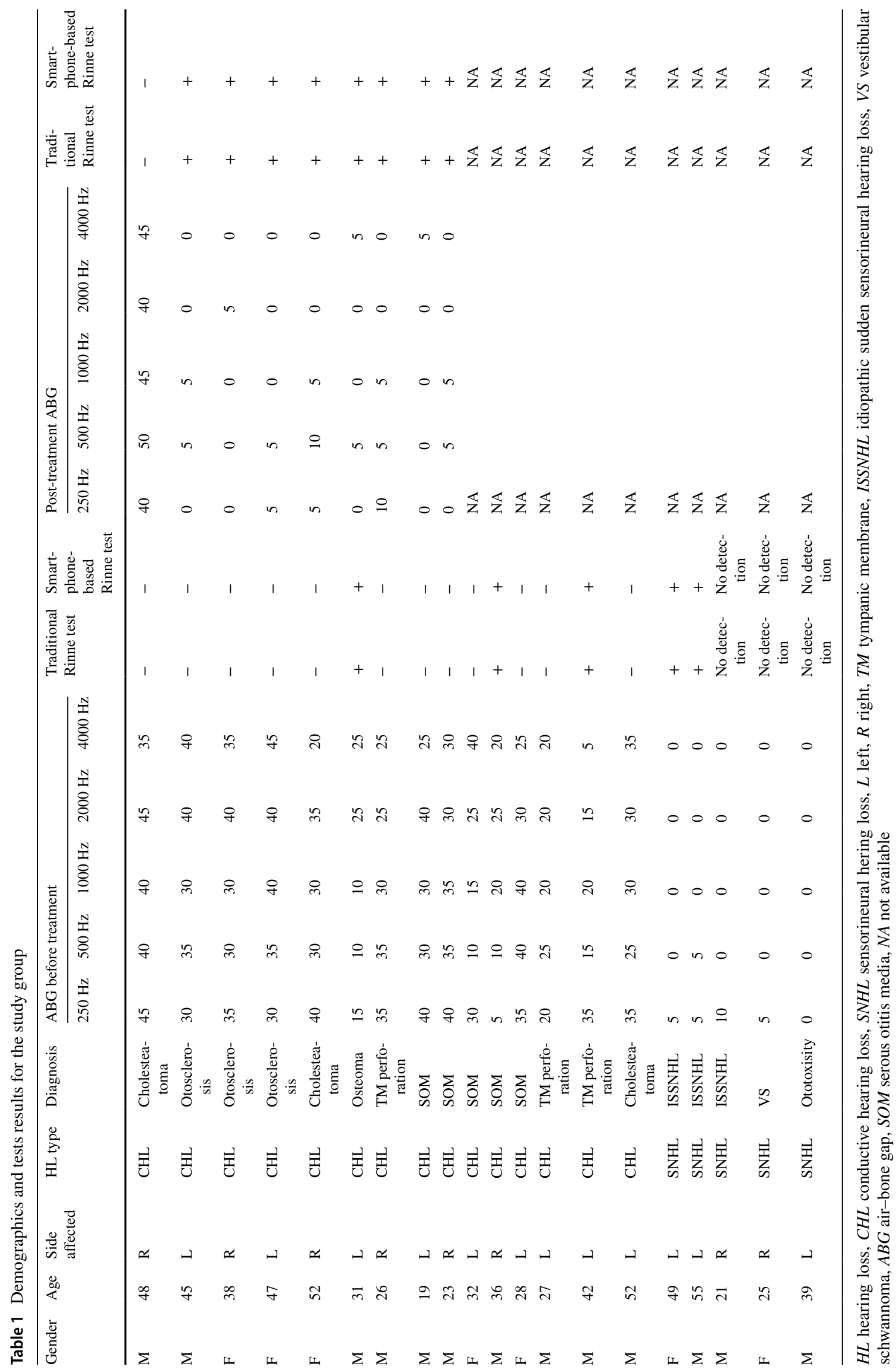


Table 2 Demographics and tests results for the control group

\begin{tabular}{|c|c|c|c|c|}
\hline Gender & Age & Side tested & Traditional Rinne test & $\begin{array}{l}\text { Smartphone- } \\
\text { based Rinne } \\
\text { test }\end{array}$ \\
\hline $\mathrm{F}$ & 69 & $\mathrm{~L}$ & + & No detection \\
\hline $\mathrm{F}$ & 33 & $\mathrm{R}$ & + & + \\
\hline M & 18 & $\mathrm{R}$ & + & + \\
\hline M & 39 & $\mathrm{~L}$ & + & + \\
\hline $\mathrm{F}$ & 32 & $\mathrm{R}$ & + & + \\
\hline $\mathrm{F}$ & 36 & $\mathrm{R}$ & + & + \\
\hline M & 32 & $\mathrm{~L}$ & + & + \\
\hline $\mathrm{F}$ & 30 & $\mathrm{~L}$ & + & + \\
\hline M & 41 & $\mathrm{~L}$ & + & + \\
\hline $\mathrm{F}$ & 58 & $\mathrm{~L}$ & + & + \\
\hline $\mathrm{F}$ & 64 & $\mathrm{~L}$ & No detection & No detection \\
\hline $\mathrm{F}$ & 54 & $\mathrm{~L}$ & + & + \\
\hline M & 33 & $\mathrm{R}$ & + & + \\
\hline M & 55 & $\mathrm{~L}$ & + & + \\
\hline M & 53 & $\mathrm{R}$ & + & + \\
\hline $\mathrm{F}$ & 47 & $\mathrm{R}$ & + & + \\
\hline M & 58 & $\mathrm{~L}$ & + & + \\
\hline M & 51 & $\mathrm{~L}$ & + & + \\
\hline M & 29 & $\mathrm{R}$ & + & + \\
\hline M & 20 & $\mathrm{R}$ & + & + \\
\hline $\mathrm{F}$ & 67 & $\mathrm{R}$ & No detection & No detection \\
\hline $\mathrm{F}$ & 19 & $\mathrm{R}$ & + & + \\
\hline $\mathrm{F}$ & 21 & $\mathrm{~L}$ & + & + \\
\hline M & 31 & $\mathrm{~L}$ & + & + \\
\hline M & 20 & $\mathrm{R}$ & + & + \\
\hline M & 47 & $\mathrm{~L}$ & + & + \\
\hline M & 40 & $\mathrm{~L}$ & + & + \\
\hline M & 58 & $\mathrm{R}$ & + & + \\
\hline M & 48 & $\mathrm{~L}$ & + & + \\
\hline $\mathrm{F}$ & 33 & $\mathrm{R}$ & + & + \\
\hline
\end{tabular}

as well. One control patient (described above) had a positive traditional Rinne test but could not detect the smartphone vibration.

\section{Discussion}

The COVID-19 pandemic highlighted the importance of telemedicine when patient interactions with healthcare providers were associated with risk of exposure to COVID-19 for both of them. As a result, patients relied on telemedicine as a primary tool for not only history taking, but also for limited physical examination. Moreover, most pure tone audiometry services became unavailable, this led to re-thinking of alternative means for diagnosis.
The Rinne test was probably first described by Adolf Rinne of Göttingen, Germany, in 1855 [2]. It was introduced into general practice 40 years later and has since become an integral part of the physical examination of patients with HLs. It is a simple and reliable tool to confirm a CHL [12], and remains the basis of the otolaryngologist's initial evaluation of hearing loss worldwide.

A systematic review of the diagnostic value of Rinne test for CHL demonstrated that the $512 \mathrm{~Hz}$ tuning fork has variable sensitivity and specificity of $16-87 \%$ and $55-100 \%$, respectively [13]. Several studies investigated parameters that can affect the accuracy of the Rinne test, such as, the tuning fork material [14], the force applied by the tuning fork against the mastoid [15], the object the tuning fork strikes to produce vibration [16], and more. As a result, many standardizations of Rinne test performance are found in different guidelines [17, 18].

Before pure tone audiometry was introduced, tuning fork tests (mainly the Rinne and Weber tests) comprised the only available tool to differentiate between CHL and SNHL. Pure tone audiometry subsequently became the gold standard for differentiating between the various types of HL [19]. Now the smartphone-based version of the Weber test has recently been validated [10]. It was also shown to reduce the time from onset of an idiopathic sudden SNHL to diagnosis [10]. Our current results demonstrate that a smartphone-based Rinne test is a legitimate option for the diagnosis of a CHL of various etiologies. The reversal of the Rinne result after the CHL condition was addressed supported its validity as a diagnostic tool for use by clinicians. Moreover, the overall accuracy of the traditional and smartphone-based Rinne tests was comparable, albeit when the latter was administered by a clinician in this investigation.

The major limitations of this study are the relatively small number of participants as well as the use of only one smartphone model for testing purposes. We are aware that the vibration frequency might differ from one smartphone model to another. In addition, testing for this validation study was administered by a clinician and not by the patients themselves.

\section{Conclusion}

The smartphone-based Rinne test is a simple and highly accessible alternative to the traditional Rinne test and with comparable accuracy. It is also potentially valid for use as a part of a telemedical physical examination.

Author contributions DH: Manuscript writing and data collection, YO: Study design, OH: Data analysis, AW: Critical revisions, GH: Literature review, OJU: Manuscript writing and data collection, this 
corresponding author contributed to study design and literature review collection.

Funding There are no financial interests, arrangements or payments to disclose.

Data availability The data that support the findings of this study are available on request from the corresponding author. The data are not publicly available due to privacy or ethical restrictions.

\section{Compliance with ethical standards}

\section{Conflict of interest None.}

Ethical approval This prospective cohort study was approved by the local (TLVMC) institutional review board (0580-20-TLV).

\section{References}

1. Burkey JM, Lippy WH, Schuring AG, Rizer FM (1998) Clinical utility of the 512-Hz Rinne tuning fork test. Am J Otol 19:59-62

2. Politzer A (1909) Diseases of the ear. Lea and Febiger, Philadelphia, pp 484-487

3. Gelfand SA (1977) Clinical precision of the Rinne test. Acta Otolaryngol 83:480-487

4. Boies LR, Hilger JA, Priest RE (1964) Fundamentals of otolaryngology. Am J Ophthalmol 58:310

5. DeWeese DD, Saunders WH (1973) Textbook of otolaryngology. St. Louis, Mo: CV Mosby, USA

6. Shambaugh GE (1967) Surgery of the ear. Saunders Co, Philadelphia

7. Ballentyne J, Groves J (1971) Scott Brown's diseases of the ear nose and throat. Ear Nose Throat 73(8):602
8. Bickley L, Szilagyi PG (2012) Bates' guide to physical examination and history-taking. Lippincott Williams and Wilkins, USA

9. Casale M, Costantino A, Rinaldi V, Forte A, Grimaldi M, Sabatino L, Oliveto G, Aloise F, Pontari D, Salvinelli F (2018) Mobile applications in otolaryngology for patients: an update. Laryngoscope Investig Otolaryngol 3(6):434-438

10. Ungar OJ, Handzel O, Cavel O, Oron Y (2019) A smartphonebased weber test may discriminate between a conductive and a sensorineural hearing loss. Audiol Neurotol 24(4):191-196

11. Butskiy O (2016) Rinne test: does the tuning fork position affect the sound amplitude at the ear? J Otolaryngol Head Neck Surg 45(1):21

12. Ng M, Jackler RK (1993) Early history of tuning-fork tests. Am J Otol 14:100-105

13. Kelly EA, Li B, Adams ME (2018) Diagnostic accuracy of tuning fork tests for hearing loss: a systematic review. Otolaryngol Head Neck Surg 159(2):220-230

14. MacKechnie CA, Greenberg JJ, Gerkin RC, McCall AA, Hirsch BE, Durrant JD, Raz Y (2013) Rinne revisited: steel versus aluminum tuning forks. Otolaryngol Head Neck Surg 149(6):907-913

15. Johnston DF (1992) A new modification of the Rinne test. Clin Otolaryngol Allied Sci 17(4):322-326

16. Samuel J, Eitelberg E (1989) Tuning forks: the problem of striking. J Laryngol Otol 103(1):1-6

17. Hallpike CS (1933) The hearing tests committee report. J Laryngol Otol 48(2):114-120

18. Hinchcliffe R (1988) Recommended procedure for Rinne and Weber tuning fork tests. Br J Audiol 22(2):153-153

19. Browning GG (1987) Is there still a role for tuning-fork tests? $\mathrm{Br}$ J Audiol 21(3):161-163

Publisher's Note Springer Nature remains neutral with regard to jurisdictional claims in published maps and institutional affiliations. 